\title{
Self-assessed level of graduating nursing students' nursing skills
}

\author{
Satu Kajander-Unkuri ${ }^{1,3}$, Riitta Suhonen ${ }^{1}$, J ouko Katajisto ${ }^{2}$, Riitta Meretoja ${ }^{1,3}$, Mikko Saarikoski ${ }^{1}$, \\ Leena Salminen ${ }^{1}$, Helena Leino-Kilpi ${ }^{1,4}$
}

1. Department of Nursing Science, University of Turku, Finland. 2. Department of Mathematics and Statistics, University of Turku, Finland. 3. Corporate Headquarters, Hospital District of Helsinki and Uusimaa, Finland. 4. Hospital District of South-West Finland, Finland.

Correspondence: Satu Kajander-Unkuri. Address: Department of Nursing Science, University of Turku, Finland. Email: satu.kajander@utu.fi

Received: July 7, 2014

DOI : 10.5430/jnep.v4n12p51
Accepted: September 21, 2014 Online Published: September 28, 2014

URL: http://dx.doi.org/10.5430/jnep.v4n12p51

\section{Abstract}

Objective: To evaluate the level of nursing skills at the point of graduation based on students' self-assessments and to identify possible related factors.

Background: Nursing skills have been identified as one of the key factors in enhancing patient safety. Maintaining patient safety is a major concern for nurses, which is why the level of graduating nurses' skills needs to be evaluated. Also, little is known about factors related to students' nursing skills.

Methods: Evaluation is based on graduating nursing students' ( $\mathrm{n}=154$, response rate $51 \%$ ) self-assessments during final clinical placements in Finnish university hospitals in 2011. Descriptive statistics and inferential statistics such as paired $T$-test, Multifactor Analysis of Covariance and Pearson/Spearman correlation coefficients were used to analyse the data.

Results: The overall level of nursing skills was self-assessed as good (75.4; VAS 0-100). Nursing skills related to the care of a dying patient was the only category assessed to be on moderate level (63.1; VAS $>57-66.8)$. The more positively the students self-assessed their readiness for practice based on nurse education and the supervisory relationship in clinical placement, the higher was the self-assessed level of nursing skills.

Conclusions: Students' assessments of their level of nursing skills should be taken into account when planning orientation and mentorship programmes for practical work to ensure safe and qualified patient care. Nurse educators should ensure that students can practice nursing skills related to care of a dying person during nurse education. A knowledge test, observation, or comparing the students' evaluations to assessments by mentors could provide a more comprehensive picture of the level of students' nursing skills.

\section{Key words}

Nursing skills, Graduating nursing student, Self-assessment, Nurse education, Competence, Clinical placement, Supervision, Multifactor Analysis of Covariance

\section{I ntroduction}

A well-educated and skilled nursing workforce is essential to the provision of safe and effective health care. Nursing skills have been identified as one of the key factors in enhancing patient safety ${ }^{[1]}$. Ensuring safe healthcare services is one of 
today's most challenging issues, especially with the increasing mobility of health professionals ${ }^{[2]}$. Although all healthcare practitioners share responsibility for ensuring patient safety, maintaining patient safety is a major concern for nurses ${ }^{[3]}$. That is why the level of graduating nursing students' (hereafter 'students') nursing skills needs to be evaluated.

Evaluation of students' nursing skills is important as there is evidence that new nurses may leave the profession during the first year after graduation ${ }^{[4,5]}$. Furthermore, the main reasons for leaving their job include inadequate clinical preparation and unrealistic professional goals ${ }^{[6]}$. All information aimed at developing retention strategies is needed as healthcare organizations need skilled staff for the provision of quality care and the maintenance of patient safety.

This study focuses on the nursing skills, which are the foundation of competence together with scientific knowledge and moral development ${ }^{[7]}$. In this study, nursing skills are defined as unique activities requiring knowledge to plan, carry out and assess accurate nursing actions in patient care. The self-assessed nursing skills in this study are nursing skills related to body temperature regulation, infection prevention, control (IP\&C) and patient hygiene, oxygenation and respiration, medication administration, pain management, cardiovascular circulation, sleep, rest and exercise, fluid balance, urinary and bowel elimination (FU\&B) and nutrition and care of a dying patient.

To bridge the gap between nurse education and practice, competence-based approaches are used to prepare nursing students to act in a complex work environment. Health care practice calls for qualified staff able to meet the demands of the work through skills and competencies they have acquired in their studies and during their career ${ }^{[8]}$. Inexperienced nurses would decrease healthcare organizations' capacity to provide services effectively ${ }^{[9]}$. A recent review of nursing students' competence areas across Europe highlighted eight main areas, including nursing skills and interventions ${ }^{[10]}$. Thus, it is important to include this skill component in nursing students' competence assessment.

There have been major changes in health care organizations around the world ${ }^{[11]}$, and they are expected to continue as populations live longer, healthcare costs continue to rise ${ }^{[12]}$ and new technological solutions make new treatments possible. The number of nursing students is increasing in many countries ${ }^{[13,14]}$ adding pressure on clinical placements. Opportunities for teaching and learning nursing skills have decreased during nurse education as nursing skill acquisition has been mostly moved from nursing schools to clinical placements. As a result, the skills acquired may be technically relevant, but theoretical justification, implementation and basis for understanding may be partly missing ${ }^{[15,16]}$. For example, in the UK, US and Sweden concerns have risen of newly graduated nurses' possible lack of nursing skill proficiency as also clinical placements are limited and learning opportunities have diminished ${ }^{[17-20]}$.

This study focused on the evaluation of students' level of nursing skills and the factors associated to these skills, at the point of graduation based on students' self-assessments. The evaluation is part of quality assurance of nurse education, particularly as students transit from school to clinical practice. The results of this study may be used for improvement of new nurses' work orientation and mentorship programmes to ensure patient safety and quality of care.

\section{Background}

Students' nursing skills as they approach graduation have been studied to some extent in recent years. Nursing skills have usually been assessed on general level as part of a research instrument ${ }^{[21-23]}$. Some researchers, however, have studied special areas of nursing skills, such as pharmacological skills ${ }^{[24,25]}$, basic technical skills (e.g. vital signs, hygiene, safety) and more advanced technical skills (e.g. wound care, medication administration ${ }^{[26,27]}$, skills in intensive and critical care $^{[28]}$, different types of cannulas and catheters and code blue skills and care of dying patients ${ }^{[29,30]}$, or a large number of basic skills ${ }^{[31]}$.

In the studies, the level of students' nursing skills is assessed as between moderate and good by self-assessment or by mentors ${ }^{[21-23]}$. A more detailed examination of the results of the studies, however, also points at gaps in the nursing skills. Gaps can be identified related to oxygenation and respiration assessment of the patient ${ }^{[28,29,31]}$, cardiovascular assess- 
ment ${ }^{[28-30]}$, taking care of hygiene and skin integrity ${ }^{[26]}$, urinary and bowel elimination and nutrition ${ }^{[26,28]}$, exercise ${ }^{[31]}$, and care of a dying patient ${ }^{[29-31]}$. In addition, there is a lack of nursing skills related to pain management ${ }^{[29]}$ and medication administration ${ }^{[24-26,29,30]}$.

Age, previous professional qualification ${ }^{[25]}$ and previous work experience ${ }^{[30]}$ seem to be associated with development of students' nursing skills. Furthermore, satisfaction with the comprehensiveness of nurse education ${ }^{[32]}$, learning opportunities and supervision in clinical placements ${ }^{[33]}$ were also related to the skills. Supervision of nursing students by mentors is critical to students' learning and professional development in clinical placement ${ }^{[34]}$, and the most important factor in students' clinical learning has been the relationship between student and mentor ${ }^{[35]}$.

In summary, previous studies have demonstrated that the level of nursing skills of students near graduation is assessed between moderate and good. Based on a more detailed investigation, there are also gaps in nursing skills. Studies have usually focused on one or two special areas of nursing skills whereas studies on multidimensional skills are scarce. Some factors have been identified to be related to the level of some specific nursing skills of students, but there is a need for further testing of these factors. This study focused on the evaluation of students' level of multidimensional nursing skills and related factors at the point of graduation. By this knowledge, it may be possible to improve new nurses' work orientation and mentorship programmes to ensure patient safety and quality of care.

\section{Methods}

\subsection{Aim}

The aim of this study was to evaluate the level of nursing skills at the point of graduation based on students' selfassessments and to identify possible factors related to nursing skills. Two research questions were set:

1) What is the level of nursing skills of students based on their self-assessments?

2) What factors are related to the level of nursing skills?

\subsection{Setting, design and sample}

This study was conducted in Finland where nurse education (bachelor degree, 3.5 years) is carried out in 23 polytechnics; 21 with education given in Finnish and 2 in Swedish. The education leads to qualification of general registered nurse without any specialisation and the content is determined on the basis of EU directive 2005/36/EC ${ }^{\text {[36, 37] }}$. Approximately 2,200 nursing students graduate each year in Finland ${ }^{[38]}$; approximately 400 of them have their final clinical placement in different units in university hospitals. When planning the study, a power analysis was done with $\mathrm{n}$ Query Advisor (power $=0.90$, alpha $=0.05$, effect size $=0.1)$ commensurate with the number of categories of background variables. The power analysis revealed a need for a minimum 148 respondents for the study. Four university hospitals (out of five) were chosen for the study because of their mutual similarity (bed number, staff number and treatment periods) ${ }^{[39]}$, as well as with wide geographical coverage.

The data were collected in February - December 2011 by an online survey. A cross-sectional survey design was employed, using a structured questionnaire among students in their last week of final clinical placements. There was a contact teacher in every polytechnic; based on information received from them, there were 302 students from 14 polytechnics in their final clinical placement in these university hospitals all of whom were invited to participate in the study. The contact teachers sent the study information letter (with the web-link of the survey) to the students by e-mail. They also sent two reminders, two and four weeks after the first contact. Students answered the survey anonymously. The sample contained 154 students (response rate 51\%) representing 9 polytechnics. 


\subsection{I nstrument}

The instrument used was modified from the validated Finnish HOTOHA instrument (Hoitotoimintojen hallinta; Command of nursing functions ${ }^{[31]}$ ). The HOTOHA is based on the literature of the psychosocial and physiological basis of nursing practice and the analysis of the aims of nursing curricula in Finland. It was designed to measure a student's command of the functions of nursing. In this study, items from the category of physical functions (originally 143) were used, because the study focused on nursing skills in these areas. Items were used after modification, i.e., removal of overlapping items. For example, patient education was studied by another instrument (results are reported elsewhere), so all items concerning patient education were removed. Terminology was updated, especially in the categories of IP\&C, hygiene and skin integrity, medication administration and pain management. The copyright holder accepted all modifications.

The modified instrument (mHOTOHA) consist of 92 items structured into 12 multidimensional nursing skill categories: IP\&C, hygiene and skin integrity, sleep and rest, exercise, FU\&B, nutrition, cardio-vascular circulation, oxygenation and respiration, body temperature regulation, medication administration, pain management and care of a dying patient (see Table 1). Each item was rated by using a Visual Analogue Scale (VAS; 0-100), with the end labelled 0 for very low and 100 for very high level of nursing skills. Students were asked to assess their technical performance and knowledge in each nursing skill. For descriptive purposes, the VAS was divided into four parts based on lower quartile, median and upper quartile to represent the level of nursing skills as low (0-57), moderate ( $>57-66.8)$, good $(>66.8-76.2)$ and very good $(>76.2-100)$.

In addition, some factors related to students' self-assessments of their nursing skills were requested. These were sociodemographic variables (student's age, gender, previous professional qualification). In addition, some variables related to the studies and career were requested [whether the students were graduating to 1st choice profession, were working in health care during semesters (yes/ no, and the number of days per month approximately) and working in paid work in health care at this moment (yes/no)]. Some factors related to the forthcoming work were requested [workplace in health care after graduation (specialized health care, primary health care, other), and considerations to leave profession]. Finally, satisfaction with the education altogether $(0=$ not satisfied at all; $10=$ very satisfied $)$, readiness for practice based on nurse education $(0=$ totally insufficient; $10=$ totally sufficient $)$, development of competence supported by supervision during clinical placement (extremely bad, bad, moderately, well, extremely well), the significance of final clinical placement for the development of competence (extremely significant, significant, moderate, not significant at all) and clinical specialty in final clinical placement were requested. In addition, two sub-dimensions of the Clinical Learning Environment and Supervision (CLES ${ }^{[35,40]}$ ) were used: supervisory relationship ( 8 items) and pedagogical atmosphere on the ward ( 9 items). Each item was rated using a scale from 0 to $10(0=$ extremely bad experience; $10=$ extremely good experience $)$.

\subsection{Ethical considerations}

Ethical approval was given by the Ethics Committee of the University of Turku and study permissions were given by each polytechnic participating in the study $(\mathrm{n}=14)$. Students' participation was voluntary, answering the on-line survey was assumed to indicate consent to participate. All information was processed confidentially ${ }^{[41]}$. Permission to use and modify the HOTOHA and to use the Finnish version of the CLES was received from the copyright holders (23.4.2010).

\subsection{Data analysis}

Data analysis was performed by using SPSS 19 (SPSS Inc., Chicago, USA) software. The data were analysed using descriptive statistics (frequencies, percentages, mean values, SD). Nine sum variables were formed out of the twelve nursing skills categories. In addition, a total nursing skill sum variable was formed from the instrument. Three out of twelve original categories were joined to other categories based on their content similarities because these categories would only have a few items. The items from the categories of hygiene and skin integrity and IP\&C were merged as a sum variable termed IP\&C and patient hygiene. FU\&B was merged with nutrition, and sleep and rest was merged with items from the category of exercise. The VAS values of the categories were calculated by adding up the item scores in each category and dividing the sum by the number of answers. The overall score of nursing skills for individual students was obtained by calculating the average of all items in all nine sum variables. 
The sample size was sufficiently large (central limit theorem) to use parametric tests without concerns of normality assumptions. Skewness was checked to be in the same direction in all groups compared. Parametric tests have more power to reveal statistically significant differences or associations between groups and they should be used in these circumstances whenever possible. Paired T-tests were used to test differences between the total nursing skill sum variable and the sum variables based on the nine categories under measurement. Multifactor Analysis of Covariance was used to model the effect of each background variable controlled by all other background variables. Sidak adjustments for multiple comparisons were used for pairwise comparisons. Dependence between continuous background variables and sum variables was analysed with Spearman and Pearson's correlation coefficient. Statistical test was considered to be significant if $p$-value was $\leq .05$. Pearson correlation test, Principal Component Analysis (PCA) and Structural Equation Model (LISREL) were used for testing validity. In addition, the reliability of the sum variables was analysed using Cronbach's alpha coefficient.

\subsection{Validity and reliability}

The content validity of the original HOTOHA has been assessed as high by careful operationalization of the concepts used in the HOTOHA and by a multi-item instrument. The content validity has also been confirmed by assessments by an expert panel ${ }^{[31]}$. In this study, the content validity of mHOTOHA was assessed by the research team and by nurse educators $(\mathrm{n}=$ 7). To test the modified instrument, a pilot study was conducted in December 2010 with students $(\mathrm{n}=17)$ in one polytechnic; based on the results, all items were relevant for students and the content validity was satisfactory. The construct validity of the original HOTOHA has been tested by factor analysis ${ }^{[31]}$ and for the mHOTOHA it was tested by Pearson correlation test, PCA with maximum likelihood estimation and by LISREL (version 8.7 used for modelling). The correlation coefficients between the sum variables and total instrument ranged from 0.679 to 0.930 supporting the construct validity. The Kaiser-Meyer-Oklin (KMO) test and Bartlett's test of sphericity were performed to determine if the PCA analysis was appropriate for the questionnaire data. The results revealed a statistical significance in the Bartlett chi-square test $(p<.001)$, the KMO value being 0.907. A KMO value $>0.5$ suggests the existence of common factors among the items. Nine principal components were formed using Kaiser Normalization with Promax rotation method because of the assumption that the components were correlated. This model explained $64.9 \%$ of the total variance of individual mHOTOHA items and supported construct validity of instrument. The LISREL model (NFI 0.97, CFI 0.98, IFI 0.98, SRMR 0.037 and GFI 0.90) also supported the construct validity. The reliability of the original HOTOHA categories has been estimated by determination of correlations and alpha-if-deleted values. In the analysis, the Cronbach's alpha coefficient for the original HOTOHA categories ranged from 0.87 to $0.96^{[31]}$. In this study, Cronbach's alpha coefficient varied from 0.87-0.94 for the categories of mHOTOHA (see Table 1).

\section{Results}

\subsection{Sample characteristics}

A total of 154 students with a mean age of 25.5 years (range 21-49 years, SD 5.1) participated in the study, $90 \%$ of them female. Before attending nurse education, $39 \%$ of respondents had a previous professional qualification, and $35 \%$ had worked in health care. During semesters, $81 \%$ of the respondents had been working in health care, and $79 \%$ were currently in paid work in health care.

Around one third (35\%) had their final clinical placement in an operative setting (operating theatre or surgical ward), around one fifth $(24 \%)$ in paediatric and (19\%) medical nursing, and 14\% in intensive care or emergency nursing. Respondents (46\%) assessed that the supervision during their final clinical placement had supported the development of their competence extremely well. Respondents' assessments of the supervisory relationship in their final clinical placement was $8.2 \pm 1.9$ (scale $0-10$ ) and of the pedagogical atmosphere on the ward $8.1 \pm 1.6$ (scale $0-10$ ). Respondents' satisfaction with the nurse education altogether was $6.3 \pm 1.7$ (scale 0-10) and readiness for practice based on nurse education $6.5 \pm 1.8$ (scale $0-10$ ). Most of the respondents (88\%) were graduating to their first choice of profession and $83 \%$ 
were going to work as nurses in specialized health care after graduation. One fifth (21\%) had already considered leaving the profession.

\subsection{Students' level of nursing skills}

The self-assessed level of nursing skills ranged from 63.1 to 81.0, mean 75.4 (see Table 1). Half (50.0\%) of the respondents assessed their level of nursing skills as very good (VAS>76.2-100) and 33.1\% as good (VAS>66.8-76.2). Almost one fifth (18.8\%) assessed their skills level as low (VAS 0-57) or moderate (VAS>57-66.8).

Table 1. The self-assessed level of nursing skills $(n=154)$

\begin{tabular}{|c|c|c|c|c|c|c|c|c|}
\hline $\begin{array}{l}\text { Nursing skills } \\
\text { category }\end{array}$ & $\begin{array}{l}\text { Number } \\
\text { items }\end{array}$ & Mean & SD & $\min$ & $\max$ & $\begin{array}{l}\text { Difference to the overall } \\
\text { level of nursing skills }\end{array}$ & $p^{*}$ & $\begin{array}{l}\text { Cronbach's } \\
\text { of Alpha }\end{array}$ \\
\hline $\begin{array}{l}\text { Body temperature } \\
\text { regulation }\end{array}$ & 5 & 81.0 & 11.5 & 20.0 & 100.0 & +5.7 & $<.001$ & 0.87 \\
\hline $\begin{array}{l}\text { IP\&C and patient } \\
\text { hygiene }\end{array}$ & 11 & 80.2 & 10.4 & 32.0 & 97.0 & +4.9 & $<.001$ & 0.89 \\
\hline $\begin{array}{l}\text { Oxygenation and } \\
\text { respiration }\end{array}$ & 8 & 78.1 & 13.1 & 13.8 & 100.0 & +2.8 & $<.001$ & 0.93 \\
\hline $\begin{array}{l}\text { Medication } \\
\text { administration }\end{array}$ & 11 & 77.7 & 11.2 & 31.8 & 100.0 & +2.4 & $<.001$ & 0.90 \\
\hline Pain management & 10 & 76.0 & 11.2 & 39.0 & 98.0 & +0.7 & .135 & 0.90 \\
\hline $\begin{array}{l}\text { Cardiovascular } \\
\text { circulation }\end{array}$ & 14 & 74.4 & 14.1 & 17.9 & 100.0 & -1.1 & .112 & 0.94 \\
\hline Sleep, rest and exercise & 9 & 74.0 & 12.4 & 22.2 & 97.8 & -1.3 & .008 & 0.90 \\
\hline FU\&B and nutrition & 17 & 73.8 & 12.7 & 25.9 & 100.0 & -1.5 & $<.001$ & 0.93 \\
\hline Care of a dying patient & 7 & 63.1 & 18.3 & 7.1 & 100.0 & -12.2 & $<.001$ & 0.91 \\
\hline Overall & 92 & 75.3 & 10.9 & 27.1 & 93.6 & & & 0.98 \\
\hline
\end{tabular}

Note. Level of nursing skills: low (0-57), moderate (>57-66.8), good (>66.8-76.2), and very good (>76.2-100); * Paired T-test

As shown in Table 1, the highest self-assessments were in nursing skills related to patient's body temperature regulation (VAS $81.0 \pm 11.5$ ) and IP\&C and patient hygiene (VAS $80.2 \pm 10.4$ ). The lowest self-assessments were in care of a dying patient (VAS $63.1 \pm 18.3)$.

Table 2. Mean differences between nursing skills categories $(n=154)$

\begin{tabular}{|c|c|c|c|c|c|c|c|c|c|}
\hline $\begin{array}{l}\text { Nursing skills } \\
\text { category }\end{array}$ & Temperat. & IP\&C... & Oxygen. & Medicat. & Pain & Cardiovasc. & Exercise & FU\&B... & $\begin{array}{l}\text { Dying } \\
\text { patient }\end{array}$ \\
\hline Main & 81.0 & 80.2 & 78.1 & 77.7 & 76.0 & 74.4 & 74.0 & 73.8 & 63.1 \\
\hline $\begin{array}{l}\text { Body } \\
\text { temperature } \\
\text { regulation }\end{array}$ & & 0.8 & $2.9 * * *$ & $3.3 * * *$ & $5.0 * * *$ & $6.6 * * *$ & $7.0^{* * *}$ & $7.2 * * *$ & $17.9 * * *$ \\
\hline $\begin{array}{l}\text { IP\&C and } \\
\text { patient hygiene }\end{array}$ & -0.8 & & 2.1 & $2.5^{*}$ & $4.2 * * *$ & $5.8 * * *$ & $6.2 * * *$ & $6.4 * * *$ & $17.1 * * *$ \\
\hline $\begin{array}{l}\text { Oxygenation } \\
\text { and respiration }\end{array}$ & $-2.9 * * *$ & -2.1 & & 0.4 & 2.1 & $3.7 * * *$ & $4.1 * * *$ & $4.3 * * *$ & $15.0^{* * *}$ \\
\hline $\begin{array}{l}\text { Medication } \\
\text { administration }\end{array}$ & $-3.3 * * *$ & $-2.5^{*}$ & -0.4 & & 1.7 & $3.3 * * *$ & $3.7 * * *$ & $3.9 * * *$ & $14.6^{* * *}$ \\
\hline $\begin{array}{l}\text { Pain } \\
\text { management }\end{array}$ & $-5.0 * * *$ & $-4.2 * * *$ & -2.1 & -1.7 & & 1.6 & $2.0 *$ & 2.2 & $12.9 * * *$ \\
\hline $\begin{array}{l}\text { Cardiovascular } \\
\text { circulation }\end{array}$ & $-6.6^{* * *}$ & $-5.8 * * *$ & $-3.7 * * *$ & $-3.3 * * *$ & -1.6 & & 0.4 & 0.6 & $11.3^{* * *}$ \\
\hline $\begin{array}{l}\text { Sleep, rest and } \\
\text { exercise }\end{array}$ & $-7.0 * * *$ & $-6.2 * * *$ & $-4.1 * * *$ & $-3.7 * * *$ & $-2.0^{*}$ & -0.4 & & 0.2 & $10.9^{* * *}$ \\
\hline $\begin{array}{l}\text { FU\&B and } \\
\text { nutrition }\end{array}$ & $-7.2 * * *$ & $-6.4 * * *$ & $-4.3 * * *$ & $-3.9 * * *$ & -2.2 & $-0.6 * * *$ & -0.2 & & $10.7 * * *$ \\
\hline $\begin{array}{l}\text { Care of a dying } \\
\text { patient }\end{array}$ & $-17.9 * * *$ & $-17.1 * * *$ & $-15.0 * * *$ & $-14.6^{* * *}$ & $-12.9 * * *$ & $-11.3 * * *$ & $-10.9 * * *$ & $-10.7 * * *$ & \\
\hline
\end{tabular}

${ }^{*} p<.05,{ }^{* *} p<.01,{ }^{* * *} p<.001$ 
As shown in Table 2, there were statistically significant differences in the self-assessments between nursing skills categories. The nursing skills category of care of a dying patient differed the most from the others.

Table 3. The 10 highest and 10 lowest level of nursing skills by items based on students' self-assessments $(\mathrm{n}=154)$

\begin{tabular}{|c|c|c|c|c|c|c|}
\hline Item & Mean & Min & Max & SD & Nursing skills category & $\begin{array}{l}\text { Difference to the } \\
\text { mean of nursing } \\
\text { skills category }\end{array}$ \\
\hline 1) Measuring body temperature & 93.4 & 0 & 100 & 8.3 & Body temperature regulation & +12.4 \\
\hline 2) Measuring blood pressure & 92.2 & 60 & 100 & 9.0 & Cardiovascular circulation & +17.8 \\
\hline 3) Assessing pulse & 92.1 & 60 & 100 & 8.9 & Cardiovascular circulation & +17.7 \\
\hline $\begin{array}{l}\text { 4) Aseptic work technique and } \\
\text { safe handling of sharp instrument }\end{array}$ & 89.9 & 60 & 100 & 9.5 & IP\&C and patient hygiene & +9.7 \\
\hline 5) Assisting with nutrition & 88.6 & 50 & 100 & 9.7 & FU\&B and nutrition & +14.8 \\
\hline $\begin{array}{l}\text { 6) Hand hygiene and use of } \\
\text { personal protective equipment }\end{array}$ & 88.4 & 50 & 100 & 10.7 & IP\&C and patient hygiene & +8.2 \\
\hline $\begin{array}{l}\text { 7) Medication administration per } \\
\text { os }\end{array}$ & 86.7 & 50 & 100 & 10.5 & Medication administration & +9.0 \\
\hline 8) Administration of oxygen & 85.0 & 30 & 100 & 12.7 & Oxygenation and respiration & +6.9 \\
\hline 9) Taking care of bed patient & 84.0 & 10 & 100 & 12.9 & IP\&C and patient hygiene & +3.8 \\
\hline $\begin{array}{l}\text { 10) Preparing and administering } \\
\text { intramuscular, intracutaneous and } \\
\text { subcutaneous injections }\end{array}$ & 83.0 & 20 & 100 & 13.2 & Medication administration & +5.3 \\
\hline \multicolumn{7}{|l|}{$\cdots \cdots$} \\
\hline 83) Inserting a nasogastric tube & 64.7 & 0 & 100 & 25.4 & FU\&B and nutrition & -9.1 \\
\hline 84) Passive exercises & 63.4 & 0 & 100 & 20.4 & Sleep, rest and exercise & -10.6 \\
\hline $\begin{array}{l}\text { 85) Preventing and taking care of } \\
\text { circulatory shock }\end{array}$ & 63.3 & 0 & 100 & 20.5 & Cardiovascular circulation & -11.1 \\
\hline $\begin{array}{l}\text { 86) Recognizing arrhythmias and } \\
\text { actions in the situation of } \\
\text { arrhythmia }\end{array}$ & 63.1 & 0 & 100 & 22.4 & Cardiovascular circulation & -11.3 \\
\hline 87) Supporting drug abusers & 60.8 & 0 & 100 & 21.0 & Medication administration & -16.9 \\
\hline $\begin{array}{l}\text { 88) Diagnostic examinations of } \\
\text { feces }\end{array}$ & 60.6 & 0 & 100 & 23.3 & FU\&B and nutrition & -13.2 \\
\hline $\begin{array}{l}\text { 89) Observation of internal } \\
\text { bleeding }\end{array}$ & 59.2 & 0 & 100 & 22.2 & Cardiovascular circulation & -15.2 \\
\hline $\begin{array}{l}\text { 90) Supporting the family of a } \\
\text { dying patient }\end{array}$ & 56.9 & 0 & 100 & 23.8 & Care of a dying patient & -6.2 \\
\hline 91) Spiritual support & 56.8 & 0 & 100 & 24.9 & Care of a dying patient & -6.3 \\
\hline $\begin{array}{l}\text { 92) Informing the family about a } \\
\text { patient's death }\end{array}$ & 51.4 & 0 & 100 & 26.7 & Care of a dying patient & -11.7 \\
\hline
\end{tabular}

As shown in Table 3, respondents assessed their own personal level of nursing skills as being on very good level in 43 out of 92 items. The ten best mean values represented items from six categories of nursing skills. Respondents self-assessed their skills level as highest in measuring body temperature and blood pressure and assessing pulse. Administration of oxygen and hand hygiene and use of personal protective equipment were also self-assessed to be on very good level. The ten lowest mean values were from five categories of nursing skills and were all assessed as being on either low or moderate level. The lowest self-assessments were seen in the category of care of a dying patient, such as supporting the family of a dying patient, spiritual support and informing the family about a patient's death. A few items in the category of cardiovascular circulation were also self-assessed on moderate level. In the category of pain management, students 
self-assessed their skills related to pharmacological treatment (VAS 80.3) higher than their skills related to nonpharmacological methods, such as relaxation (VAS 69.8) and breathing techniques and positioning (VAS 67.5).

\subsection{Factors related to nursing skills}

The overall self-assessed level of nursing skills correlated positively with pedagogical atmosphere on the ward $(r=0.264$, $p=.001)$, supervisory relationship $(r=0.249, p=.002)$, satisfaction with the nurse education $(r=0.251, p=.002)$ and readiness for practice based on nurse education $(r=0.343, p<.001)$.

Table 4. The correlations between nursing skills related factors and nursing skills categories $(\mathrm{n}=154)$

\begin{tabular}{lllll}
\hline Nursing skills category & $\begin{array}{l}\text { Supervisory } \\
\text { relationship }\end{array}$ & $\begin{array}{l}\text { Pedagogical } \\
\text { atmosphere on the } \\
\text { ward }\end{array}$ & $\begin{array}{l}\text { Satisfied with } \\
\text { the education } \\
\text { altogether }\end{array}$ & $\begin{array}{l}\text { Readiness for practice } \\
\text { based on nurse } \\
\text { education }\end{array}$ \\
\hline Body temperature regulation & $0.348^{* * *}$ & $0.316^{* * *}$ & $0.212^{* *}$ & $0.301^{* * *}$ \\
IP\&C and patient hygiene & $0.180^{*}$ & $0.221^{* *}$ & $0.304^{* * *}$ & $0.428^{* * *}$ \\
Oxygenation and respiration & $0.379^{* * *}$ & $0.340^{* * *}$ & $0.190^{*}$ & $0.270^{* *}$ \\
Medication administration & $0.292^{* * *}$ & $0.289^{* * *}$ & $0.169^{*}$ & $0.306^{* * *}$ \\
Pain management & $0.204^{*}$ & $0.279^{* * *}$ & $0.228^{* *}$ & $0.259^{* *}$ \\
Cardiovascular circulation & $0.340^{* * *}$ & $0.322^{* * *}$ & 0.126 & $0.217^{* *}$ \\
Sleep, rest and exercise & $0.240^{* *}$ & $0.285^{* * *}$ & $0.237^{* *}$ & $0.345^{* * *}$ \\
FU\&B and nutrition & $0.217^{* *}$ & $0.224 * *$ & $0.253^{* *}$ & $0.365^{* * *}$ \\
Care of a dying patient & 0.149 & $0.178^{*}$ & $0.255^{* *}$ & $0.175^{*}$ \\
\hline$*$ * & & & &
\end{tabular}

$* p<.05, * * p<.01, * * * p<.001$

As shown in Table 4, almost all nursing skills categories had a positive statistically significant correlation with these factors. The strongest correlations were seen between readiness for practice based on nurse education and IP\&C and patient hygiene $(r=0.428)$ and between supervisory relationship and oxygenation and respiration $(r=0.379)$.

Table 5. The multifactor analysis of the nursing skills category and nursing skills related factors

\begin{tabular}{|c|c|c|c|c|}
\hline Nursing skills category & Nursing skills related factor & $\mathbf{F}$ & $p$ & $\begin{array}{l}\text { Partial Eta } \\
\text { Squared ( } \eta 2)\end{array}$ \\
\hline IP\&C and patient hygiene & Readiness for practice based on nurse education & 12.288 & 0.001 & 0.093 \\
\hline Care of a dying patient & No intention to leave profession & 10.010 & 0.002 & 0.077 \\
\hline \multirow{3}{*}{ Medication administration } & Readiness for practice based on nurse education & 9.074 & 0.003 & 0.070 \\
\hline & Working at this moment in paid work in health care & 5.232 & 0.024 & 0.042 \\
\hline & $\begin{array}{l}\text { Competence was extremely significantly developed } \\
\text { by the final clinical placement }\end{array}$ & 4.156 & 0.044 & 0.033 \\
\hline Sleep, rest and exercise & Readiness for practice based on nurse education & 8.229 & 0.005 & 0.064 \\
\hline \multirow{2}{*}{ FU\&B and nutrition } & Readiness for practice based on nurse education & 8.180 & 0.005 & 0.064 \\
\hline & Working at this moment in paid work in health care & 8.169 & 0.005 & 0.064 \\
\hline \multirow{2}{*}{ Cardiovascular circulation } & Supervisory relationship & 5.855 & 0.017 & 0.047 \\
\hline & Gender & 3.922 & 0.050 & 0.032 \\
\hline \multirow{2}{*}{ Oxygenation and respiration } & Supervisory relationship & 5.985 & 0.016 & 0.048 \\
\hline & Readiness for practice based on nurse education & 4.257 & 0.041 & 0.034 \\
\hline \multirow{3}{*}{$\begin{array}{l}\text { Body temperature } \\
\text { regulation }\end{array}$} & No intention to leave profession & 5.841 & 0.017 & 0.046 \\
\hline & Readiness for practice based on nurse education & 5.798 & 0.018 & 0.046 \\
\hline & Supervisory relationship & 4.699 & 0.032 & 0.038 \\
\hline Pain management & ns & & & \\
\hline
\end{tabular}

Note. $\mathrm{ns}=$ no significant related factors; $\eta \mathrm{p} 2=$ is the proportion of variance in the dependent variable (nursing skills' category) explained by the independent variable (nursing skills related factor) 
As shown in Table 5 based on Multifactor Analysis of Covariance, the more positively the student assessed her readiness for practice based on nurse education, the higher was the self-assessed level of nursing skills $(p=.012)$. This factor was found to be statistically significantly related with six nursing skills categories. Also supervisory relationship was statistically significantly related with three nursing skills categories.

\section{Discussion}

\subsection{Discussion of the students' nursing skills}

Overall, the students self-assessed their level of nursing skills as good. These findings are congruent with previous studies ${ }^{[8,23]}$. Compared to the previous study with the original HOTOHA ${ }^{[31]}$ in 1999, students' level of nursing skills at the point of graduation are now higher in every nursing skills category than previously assessed. However, during their clinical placements, students practice under supervision and they are not responsible for nurses' duties. According to a previous study ${ }^{[42]}$, awareness of nurses' responsibilities has been found to differ between students and graduate nurses, and it seems that students trust their competence near graduation ${ }^{[23,43,44]}$. In this study, students were asked to evaluate their nursing skills, including also knowledge of every nursing skill. It is, however, possible that students have evaluated only their technical skills. The evaluation of nursing skills may be more difficult because it requires students to think critically ${ }^{[45]}$, and earlier studies ${ }^{[23,26]}$ indicate that students have difficulties in critical thinking. Based on the results, almost one fifth assessed their skills level as low or moderate. Students with low self-assessment of their level of nursing skills should be recognised during nurse education in order to plan special support for their clinical training. Students' different self-assessments of their level of nursing skills should be taken into account when planning orientation and mentorship programmes for practical work. This would ensure that newly qualified nurses can practice safely although the assessments of the level of nursing skills might have been unrealistically high or low at the point of graduation. The development of nursing skills during nurse education should be studied in a longitudinal setting to improve goal setting for different types of clinical training in collaboration between educators and nursing practice.

Nursing skills related to medication administration have been a global concern ${ }^{[24,25]}$. In this study, however, medication administration was self-assessed as very good. This is a good result for nurse education, as theoretical training has been developed to increase medication competence. It is also a good result for healthcare organizations, as safe and effective medication administration is an important component of nurses' responsibilities and one key factor of patient safety. In earlier studies, nursing skills related to medication administration prior to graduation were found to be limited by students' self-assessment ${ }^{[24,25,29,30]}$, and students did not perceive themselves as able to deliver safe medication care in practice $^{[24,26]}$. The development of medicine and new technological solutions has made new treatments possible for the growing amount of people with chronic conditions, such as diabetes and cardiovascular diseases. In Europe, an increasing number of people are living with chronic conditions ${ }^{[46]}$. Medication is an essential part of care of these chronic conditions, which is why nurses' adequate nursing skills related to medication administration are highly important. The use of medication among older people has increased in the past decades ${ }^{[47]}$ and in acute care patients' medication can change daily and the use of high alert medication requires special caution. Nurses play a vital role in identifying patients' need for medication and in evaluating medication treatment. Although the results of this study indicate that students self-assessed their nursing skills related to medication administration to be on very good level, more research on nursing skills related to students' medication administration is still needed.

The key part of the safety and quality of care is that patients have no pain. Nursing skills related to pain management was self-assessed as good. However, students' self-assessed their skills related to pharmacological treatment higher than their skills related to nonpharmacological methods. Nurses are in a key position for suggesting different kinds of pain management methods in addition to pharmacological treatment ${ }^{[48]}$ for treating pain. Nonpharmacological methods are used very little ${ }^{[49]}$, although listening to music, for example, has a positive effect on blood pressure, heart rate, and 
respiratory rate after surgery ${ }^{[50]}$. Students should be encouraged to strengthen their knowledge of the benefits of nonpharmacological methods for treating pain.

Infection prevention and control is an ongoing issue worldwide as approximately 50,000 deaths are estimated to occur across Europe every year due to healthcare-associated infections (HCAIs) ${ }^{[51]}$. New viruses, such as Ebola, also require adherence to IP\&C guidelines, and multiresistant bacteria are a growing problem in health care. In this study, students self-assessed their nursing skills related to IP\&C and patient hygiene as very good. However, according to a systematic review ${ }^{[52]}$, the median compliance rate of hand hygiene has been only $40 \%$ in hospital care. As future practitioners, students have an important role to play in preventing HCAIs and maintaining patient safety from the viewpoint of IP\&C.

Students' self-assessed their nursing skills related to patients' vital signs i.e. body temperature regulation, oxygenation and respiration and cardiovascular circulation, on either good or very good level. However, when this was investigated at item level, there were also gaps in nursing skills related to cardiovascular circulation. These gaps, for example "observation of internal bleeding", "recognizing arrhythmias and actions in the situation of arrhythmia" and "preventing and taking care of circulatory shock" can cause a life-threatening situation for the patient and these situations need to be strengthened during theoretical and clinical training.

Care of a dying patient was reported as the nursing skill with the lowest self-assessed level of nursing skills, which is in line with earlier studies ${ }^{[29-31,53]}$. It was the only nursing skills category assessed on moderate level and the variation of self-assessment was high. This might be the result of lack of education or limited focus in the curriculum, or the fact that many nursing students and even nurses have difficulties in dealing with death. As death rates in specialized health care are low and students spend most of their clinical training practicing in specialized health care, opportunities to practice nursing skills related to the care of a dying patient are limited. This lack of education has decreased the level and quality of end-of-life care provided to patients ${ }^{[33,54]}$. Therefore, when planning nurse curricula, the low level of nursing skills related to care of a dying person should be taken into account. For example, the use of simulation to teach students how to inform the family about the death of a patient and how to support the family of a dying patient could be one useful strategy. When planning orientation for practical work, this skills area should be recognised. Nurses take care of dying patients and their families and students benefit from having developed these skills before graduation, although they cannot be experts in providing care to dying patients at the point of graduation.

Based on the understanding that students' self-assessments of their skill levels are accurate, nurse education had been successful in preparing them to perform nursing skills, and the concerns of earlier studies ${ }^{[17-20]}$ that newly graduated nurses lack proficiency in nursing skills are currently not warranted. However, according to previous studies, new nurses are leaving their jobs or even the profession due to inadequate clinical preparation and unrealistic professional goals ${ }^{[6]}$. This leads to the question of whether the current nurse education offers sufficient readiness for practice required in specialized health care. Instead of practicing specific nursing skills during theoretical and clinical training, the focus should be on comprehensive care of the patient. The use of simulation to connect specific nursing skills with comprehensive care of the patient and longer clinical placements could be useful strategies ${ }^{[34]}$.

\subsection{Discussion of the related factors}

The readiness for practice based on nurse education was found to be a significant factor related to the level of multidimensional nursing skills and to almost all nursing skills categories. The most important element in clinical placement was the supervisory relationship with the mentor during the final clinical placement, as has already been indicated already in earlier studies ${ }^{[33-35]}$. There can be many nursing students in clinical placements at the same time and mentors may sometimes feel exhausted, but students need individual support and guidance during their clinical training, together with confidential supervision sessions where they can reflect on their learning and achieve a realistic awareness of nurses' responsibilities. 
One fifth $(21 \%)$ of the students had already considered leaving the profession, and this background factor was found to be a significant factor related to care of a dying patient. It might be that these students are not fully committed to the nurse's role and their future profession, and these students should be recognized during the clinical training. It might be that students who had already considered leaving the profession, had no experiences of caring a dying patient and felt more unsure of their nursing skills than other students.

Current paid work in healthcare was related to the nursing skills related to medication administration. In our study, $79 \%$ were in paid work in health care at the time of study, and they may be higher up on the ladder in terms of experience, confidence and ability to work in a health care environment compared to those who have not had so much nursing experience. This might indicate that students do not have enough opportunities to practice nursing skills related to medication administration during nurse education, and this ought to be taken into account during theoretical training. The background factor "competence was extremely significantly developed by the final clinical placement" was also related to the nursing skills related to medication administration. The final clinical placement is usually the longest clinical placement in nurse education in Finland. It takes place during the final semester when all theoretical studies have been completed. It might be that during final clinical placement, students have more opportunities to practice nursing skills related to medication administration as they have gained a theoretical understanding of comprehensive medication administration.

\subsection{Study limitations}

There are some limitations related to the validity and reliability of our study. First, the moderate response rate (51\%) might have influenced the study results, and the generalizability of the results is limited due to the sample size. It is surmised that nursing students place a high value on their time and may not have viewed completion of an on-line survey as "high-priority" use of their time outside of class. Our contact teachers sent two reminders of the study to students to get them to participate. The sample was, however, representative of the population of Finnish graduating nursing students by demographic data (age and gender) of the students ${ }^{[5]}$ and by geographical location of the university hospitals and polytechnics. Second, the instrument was modified from the validated Finnish HOTOHA instrument ${ }^{[31]}$. In spite of the modification, the internal consistency among nursing skills categories remained high (0.87-0.94). Pearson correlation test, PCA with maximum likelihood estimation with nine principal components and LISREL all supported the construct validity of the mHOTOHA, so it can be considered a valid instrument. The limitation of the MHOTOHA is that it is based on self-assessment, and it has been observed in earlier studies that students tend to overestimate their assessments ${ }^{[23,43,44]}$. However, self-assessment is an important element of multi-method assessment strategy ${ }^{[56,57]}$ and essential for learning critical thinking ${ }^{[58]}$, and it should be used during nurse education to teach students to assess themselves. For learning evaluation, however, it would be useful for students to have opportunity to compare their self-assessments with those of mentors. In addition, in future studies, patients' assessments of students' nursing skills should also be included ${ }^{[59]}$. The students had answered all items carefully and no questionnaires were rejected in the data analysis. Third, as the empirical data were collected from Finnish students, it should be pointed out that cultural and environmental differences always bring some limitations to generalizing the empirical findings internationally.

\section{Conclusion}

The students participating in this study indicated a high level of nursing skills. As skills are one of the foundations of competence, the results of this study give a viewpoint of skills on students' competence. The readiness for practice based on nurse education was related to the level of nursing skills and nursing skills categories. Supervision in the clinical learning environment was also an important factor related to the nursing skills categories. This knowledge could contribute to discussion on how to develop and evaluate the nursing skills of new nurses. The mHOTOHA is a valid instrument to assess the level of nursing skills of students and using it in different European countries would help to develop nurse education in Europe where it is based on the same Directive ${ }^{[36]}$. However, in the future, as nurses' roles in 
health care expand and the number of nurses having their own practice increases, diagnostic skills and skills related to evaluating care could be additional areas to be added into the mHOTOHA. Comparing the evaluations of students to assessments by mentors, or even by patients, as well as observation or knowledge tests could be used alongside self-assessment to give a more comprehensive picture of the level of students' nursing skills and support students to gain a realistic perception of their nursing skills, which is an important requirement for practicing nurses. Nurses who cannot accurately self-assess their competence may be at greater risk of providing suboptimal care to patients. For a nursing student, graduation is the beginning of lifelong learning and the development of competence in the role of a registered nurse. For healthcare organizations, assessment is a first step in evaluating in an accurate and efficient manner the strengths and weaknesses of new nurses as they transition from school to the workplace.

\section{Acknowledgements}

We would like to thank all the graduating nursing students who participated in this study and the contact teachers in all polytechnics in Finland who kindly supported with the data collection and Anna Vuolteenaho for her expertise with the English language. The study was funded by the Finnish Nurses Association, Finnish Concordia Fund, the Finnish Work Environment Fund and Finnish Foundation for Nursing Education, which are gratefully acknowledged.

\section{References}

[1] Alfredsdottir H, Bjornsdottir K. Nursing and patient safety in the operating room. Journal of Advanced Nursing. 2008 Jan; 61(1): 29-37. http://dx.doi.org/10.1111/j.1365-2648.2007.04462.x.

[2] Stievano A, Jurado MG, Rocco G, Sasso L. A new information exchange system for nursing professionals to enhance patient safety across Europe. Journal of Nursing Scholarship. 2009 4th Quarter; 41(4): 391-398. http://dx.doi.org/10.1111/j.1547-5069.2009.01307.x.

[3] Kohlbrenner J, Whitelaw G, Cannaday D. Nurses critical to quality, safety, and now financial performance. Journal of Nursing Administration. 2011 Mar; 41(3): 122-128. http://dx.doi.org/10.1097/NNA.0b013e31820c71f9

[4] Duchscher, JB. Transition shock: The initial stage of role adaptation for newly graduated registered nurses. Journal of Advanced Nursing. 2009 May; 65(5): 1103-1113. http://dx.doi.org/10.1111/j.1365-2648.2008.04898.x

[5] Flinkman M, Laine M, Leino-Kilpi H, Hasselhorn H, Salanterä S. Explaining young registered Finnish nurses' intention to leave the profession: a questionnaire survey. International Journal of Nursing Studies. 2008 May; 45(5): 727-739. http://dx.doi.org/10.1016/j.ijnurstu.2006.12.006

[6] Hayman-White K, Happell B, Charleston R, Ryan R. Transition to mental health nursing through specialist graduate nurse programs in mental health: a review of the literature. Issues in Mental Health Nursing. 2007 Feb; 28(2): 185-200. http://dx.doi.org/10.1080/01612840601096354.

[7] Epstein RM, Hundert EM. Defining and assessing professional competence. Journal of the American Medical Association. 2002 Jan; 287(2): 226-235. http://dx.doi.org/10.1001/jama.287.2.226

[8] Perng S-J, Watson R. Psychometric testing of an instrument measuring core competencies of nursing students. Advance in Nursing Science. 2013 Apr-Jun; 36(2): 146-157. http://dx.doi.org/10.1097/ANS.0b013e3182902020

[9] Aiken LH, Clarke SP, Sloane DM, Sochalski J, Silber JH. Hospital nurse staffing and patient mortality, nurse burnout, and job dissatisfaction. Journal of the American Medical Association. 2002 Oct; 288(16): 1987-1993. http://dx.doi.org/10.1001/jama.288.16.1987

[10] Kajander-Unkuri S, Salminen L, Saarikoski M, Suhonen R, Leino-Kilpi H. Competence areas of nursing students in Europe. Nurse Education Today. 2013 Jun; 33(6): 625-632. http://dx.doi.org/10.1016/j.nedt.2013.01.017

[11] Auerbach DI, Staiger DO, Muench U, Buerhaus PI. The nursing workforce in an era of health care reform. New England Journal of Medicine. 2013 Apr; 368: 1470-1472. http://dx.doi.org/10.1056/NEJMp1301694

[12] Chreim S, Williams BE, Coller KE. Radical change in healthcare organization: Mapping transition between templates, enabling factors, and implementation processes. Journal of Health Organization and Management. 2012 26(2): 215-236. http://dx.doi.org/10.1108/14777261211230781

[13] Barnett T, Cross M, Shahwan-Akl L, Jacob E. The evaluation of a successful, collaborative education model to expand student clinical placements. Nurse Education in Practice. 2010 Jan; 10(1): 17-21. http://dx.doi.org/10.1016/j.nepr.2009.01.018

[14] Benner P, Sutphen M, Leonard V, Day L. Educating Nurses: A Call for Radical Transformation. San Francisco: Jossey-Bass; 2010 . 
[15] Borneuf A-M, Haigh C. The who and where of clinical skills teaching: A review from the UK perspective. Nurse Education Today. 2010 Feb; 30(2): 197-201. http://dx.doi.org/10.1016/j.nedt.2009.07.012

[16] Robinson BK, Dearmon V. Evidence-based nursing education: Effective use of instructional design and simulated learning environments to enhance knowledge transfer in undergraduate nursing students. Journal of Professional Nursing. 2013 Jul-Aug; 29(4): 203-209. http://dx.doi.org/10.1016/j.profnurs.2012.04.022

[17] Athlin E, Larsson M, Söderhamn O. A model for a national clinical final examination in the Swedish bachelor programme in nursing. Journal of Nursing Management. 2012 Jan; 20(1): 90-101. http://dx.doi.org/10.1111/j.1365-2834.2011.01278.x

[18] Berkov S, Virkstis K, Steward J, Conway L. Assessing new graduate nurse performance. The Journal of Nursing Administration. 2008 Nov; 38(11): 468-474. http://dx.doi.org/10.1097/01.NNA.0000339477.50219.06

[19] Bradshaw A, Merriman C. Nursing competence 10 years on: fit for practice and purpose yet? Journal of Clinical Nursing. 2008 May; 17(10): 1263-1269. http://dx.doi.org/10.1111/j.1365-2702.2007.02243.x.

[20] Higgins G, Spencer RL, Kane R. A systematic review of the experience and perceptions of the newly qualified nurse in the United Kingdom. Nurse Education Today. 2009 Aug; 30(6): 499-508. http://dx.doi.org/10.1016/j.nedt.2009.10.017

[21] Clinton M, Murrels T, Robinson S. Assessing competency in nursing: a comparison of nurses prepared through degree and diploma programmes. Journal of Clinical Nursing. 2005 Jan; 14(1): 82-94. http://dx.doi.org/10.1111/j.1365-2702.2004.01015.x

[22] Kajander-Unkuri S, Meretoja R, Katajisto J, Salminen L, Saarikoski M, Suhonen R, Leino-Kilpi H. Self-assessed level of competence of graduating nursing students and factors related to it. Nurse Education Today. 2014 May; 34(5): 795-801. http://dx.doi.org/10.1016/j.nedt.2013.08.009

[23] Löfmark A, Smide B, Wikblad K. Competence of newly-graduated nurses - a comparison of the perceptions of qualified nurses and students. Journal of Advanced Nursing. 2006 Mar; 53(6): 721-728. http://dx.doi.org/10.1111/j.1365-2648.2006.03778.x

[24] Dilles T, Vander Stichele RR, Van Bortel L, Elseviers MM. Nursing students' pharmacological knowledge and calculation skills. Ready for practice? Nurse Education Today. 2011 Jul; 31(5): 499-505. http://dx.doi.org/10.1016/j.nedt.2010.08.009

[25] Grandell-Niemi H, Hupli M, Leino-Kilpi H, Puukka P. Finnish nurses' and nursing students' pharmacological skills. Journal of Clinical Nursing. 2005 Jul; 14(6): 685-694. http://dx.doi.org/10.1111/j.1365-2702.2005.01131.x

[26] Hickey MT. Preceptor Perceptions of New Graduate Nurse Readiness for Practice. Journal for Nurses in Staff Development. 2009 Jan-Feb; 25(1): 35-41. http://dx.doi.org/10.1097/NND.0b013e318194b5bb

[27] O'Connor SE, Pearce J, Smith RL, Voegeli D, Walton P. An evaluation of the clinical performance of newly qualified nurses: a competency based assessment. Nurse Education Today. 2001 Oct; 21(7): 559-568. http://dx.doi.org/10.1054/nedt.2001.0594

[28] Ääri R-L, Ritmala-Castrén M, Leino-Kilpi H, Suominen T. Biological and physiological knowledge and skills of graduating nursing students to practice in intensive care. Nurse Education Today. 2004 May; 24(4): 293-300. http://dx.doi.org/10.1016/j.nedt.2004.02.003

[29] Casey K, Fink R, Krugman M, Propst J. The graduate nurse experience. Journal of Nursing Administration. 2004 Jun; 34(6): 303-310. PMid:15190226 http://dx.doi.org/10.1097/00005110-200406000-00010

[30] Marshburn DM, Engelke MK, Swanson MS. Relationships of new nurses' perceptions and measured performance-based clinical competence. Journal of Continuing Education in Nursing. 2009; 40(9): 426-432. http://dx.doi.org/10.3928/00220124-20090824-02

[31] Räisänen A. Level of know-how of persons graduating nurses [dissertation]. [Turku]: University of Turku; 2002.270 p. [in Finnish].

[32] Grandell-Niemi H, Hupli M, Puukka P, Leino-Kilpi H. Finnish nurses' and nursing students' mathematical skills. Nurse Education Today. 2006 Feb; 26(2): 151-161. http://dx.doi.org/10.1016/j.nedt.2005.08.007

[33] Houghton CE, Casey D, Shaw D \& Murphy K. Students' experiences of implementing clinical skills in the real world of practice. Journal of Clinical Nursing. 2013 Jul; 22(13-14): 1961-1969. http://dx.doi.org/10.1111/jocn.12014

[34] Warne T, Johansson U-B, Papastavrou E, Tichelaar E, Tomietto M, Van den Bossche K, Moreno MFV, Saarikoski M. An exploration of the clinical learning experience of nursing students in nine European countries. Nurse Education Today. 2010 Nov; 30(8): 809-815. http://dx.doi.org/10.1016/j.nedt.2010.03.003.

[35] Saarikoski M, Leino-Kilpi H. The clinical learning environment and supervision by staff nurses: developing the instrument. International Journal of Nursing Studies. 2002 Mar; 39(3): 259-267. http://dx.doi.org/10.1016/S0020-7489(01)00031-1

[36] European Commission. Directive 2005/36/EC [Internet]. Official Journal of the European Union [revised 2005 Sep 30 ; cited 2014 Jul 4]. Available from:

http://www.nepes.eu/files/Directive\%202036\%20Recognition\%20of\%20professional\%20qualification\%20EN.pdf

[37] Ministry of Education. Polytechnics [Internet]. Ministry of Education and Culture [revised 2010; cited 2014 Jul 4]. Available from: http://www.minedu.fi/OPM/Koulutus/ammattikorkeakoulutus/ammattikorkeakoulut/?lang=en. 
[38] Ministry of Education and Culture. Qualification of polytechnics [Internet]. Ministry of Education and Culture [revised 2012; cited 2014 Jul 4]. Available from: http://vipunen.csc.fi/fi-fi/ammattikorkeakoulutus/ammattikorkeakoulutusraportit/AMK.tutkinnot_ala.xlsx [in Finnish].

[39] National Institute of Health and Welfare. Productivity of the hospitals. Statistical report 1/2012 [Internet]. National Institute of Health and Welfare [revised 2012 Jan 30; cited 2014 Jul 4]. Available from: http://urn.fi/URN:NBN:fi-fe201205085318 [in Finnish]

[40] Saarikoski M, Isoaho H, Warne T, Leino-Kilpi H. The nurse teacher in clinical practice: Developing the new sub-dimension to the clinical learning environment and supervision (CLES) scale. International Journal of Nursing Studies. 2008 Aug; 45(8): 1233-1237. http://dx.doi.org/10.1016/j.ijnurstu.2007.07.009

[41] Pauwels E. Ethics for researchers. Facilitating Research Excellence in FP7 [Internet]. Luxembourgh. Office for official publications of the European Communities [revised 2007; cited 2014 Jul 4]. Available from: http://www.eurosfaire.prd.fr/7pc/doc/1174577397_ethics_for_researchers.pdf.

[42] Wangensteen S, Johansson IS, Nordström G. The first year as a graduate nurse - An experience of growth and development. Journal of Clinical Nursing. 2008 Jul; 17(14): 1877-1885. http://dx.doi.org/10.1111/j.1365-2702.2007.02229.x

[43] Baxter P, Norman G. Self-assessment or self deception? A lack of association between nursing students' self-assessment and performance. Journal of Advanced Nursing. 2011 Nov; 67(11): 2406-2413. http://dx.doi.org/10.1111/j.1365-2648.2011.05658.x

[44] Lakanmaa R-L, Suominen T, Perttilä J, Ritmala-Castrèn M, Vahlberg T, Leino-Kilpi H. Graduating nursing students' basic competence in intensive and critical care nursing. Journal of Clinical Nursing. 2014 Mar; 23(5-6): 645-653. http://dx.doi.org/10.1111/jocn.12244.

[45] Fitzpatrick J. Self-assessment as a strategy to provoke integrative learning within a professional degree programme. Learning in Health and Social Care. 2006; 5(1): 23-34. http://dx.doi.org/10.1111/j.1473-6861.2006.00114.x

[46] WHO. Nursing and midwifery/ human resources for health. Global standards for the initial education of professional nurses and midwifes (WHO/HRH/HPN/08.6). Geneva, Switzerland.

[47] Hajjar ER, Cafiero AC, Hanlon JT. Polypharmacy in elderly patients. The American Journal of Geriatric Pharmacotherapy. 2007 Dec; 5(4): 345-351. http://dx.doi.org/10.1016/j.amjopharm.2007.12.002.

[48] Dunn K. Music and the reduction of post-operative pain. Nursing Standard. 2004 May; 18(36): 33-39. PMid:15176110 http://dx.doi.org/10.7748/ns2004.05.18.36.33.c3612

[49] Tracy SM. Piloting tailored teaching on nonpharmacologic enhancements for postoperative pain management in older adults. Pain Management Nursing. 2010 Sep; 11(3): 148-158. http://dx.doi.org/10.1016/j.pmn.2009.06.002

[50] Vaajoki A. Postoperative pain in adult gastroenterological patients - music intervention in pain alleviation. [dissertation]. [Kuopio]: University of Eastern Finland; 2012. 100 p.

[51] European Centre for Disease Prevention and Control. The First European Communicable Disease Epidemiological Report. Stockholm: European Centre for Disease Prevention and Control. 390 p.

[52] Erasmus V, Daja TJ, Brug H, Richardus JH, Behrendt MD, Vos MC, van Beeck EF. Systematic review of studies on compliance with hand hygiene guidelines in hospital care. Infection Control and Hospital Epidemiology. 2010 Mar; 31(3): $283-294$. http://dx.doi.org/10.1086/650451.

[53] Mallory JL, Allen C. Care of the Dying: A Positive Nursing Student Experience. Medsurg Nursing. 2006 Aug; 15(4): $217-222$. PMid:16999183

[54] Moreland SS, Lemieux ML, Myers A. End-of-life Care and the Use of Simulation in a Baccalaureate Nursing Program. International Journal of Nursing Education Scholarship. 2012 Jun; 9(1): http://dx.doi.org/10.1515/1548-923X.2405

[55] Stenström M-L, Virolainen M, Vuorinen-Lampila P, Valkonen S. Student careers in vet and higher education. Finnish Institute for Educational Research Reports 45 [Internet] University of Jyväskylä [revised 2012; cited 2014 Jul 4] Available from: http://ktl.jyu.fi/img/portal/23031/g045.pdf [in Finnish]

[56] Norman IJ, Watson R, Murrels T, Calman L, Redfern S. The validity and reliability of methods to assess the competence to practise of pre-registration nursing and midwifery students. International Journal of Nursing Studies. 2012 Feb; 39(2): $133-145$. http://dx.doi.org/10.1016/S0020-7489(01)00028-1

[57] Watson R, Stimpson A, Topping A, Porock D. Clinical competence assessment in nursing: a systematic review of the literature. Journal of Advanced Nursing. 2002 Sep; 39(5): 421-431. PMid:12175351 http://dx.doi.org/1046/j.1365-2648.2002.02307.x

[58] Segers M, Dochy F. New assessment forms in problem-based learning: The value added of the students' perspective. Studies in Higher Education. 2001; 26(3):327-343 http://dx.doi.org/10.1080/03075070120076291

[59] Suikkala, A. Nursing student-patient relationship and associated factors. [dissertation]. [Turku]: University of Turku; 2007. 174p. 